\title{
MALVINAS, LAS ISLAS PROMETIDAS. APROXIMACIONES A LA LITERATURA DE LA GUERRA
}

\author{
Luz C. Souto \\ Universitat de València, Valencia, España \\ luz.souto@uv.es
}

\section{RESUMEN / ABSTRACT}

El presente artículo propone, en primer lugar, un acercamiento a la construcción nacional del relato sobre las Islas Malvinas. En segunda instancia se realiza un recorrido por la literatura que aborda la guerra de Malvinas a partir de tres focos narrativos: 1982-1989, 1990-2001 y 2002-2017. La periodización responde a las diferentes generaciones pero también a los procesos sociales que han acompañado una transformación política y cultural en Argentina. Finalmente, y como modo de detectar los principales géneros, tramas y conflictos narrativos que han surgido hasta este momento, se analizan las obras más representativas de cada periodo.

PALABRAS ClaVe: Islas Malvinas, guerra, literatura argentina, memoria histórica, relato nacional.

\section{FALKLAND, THE PROMISED ISLANDS. APPROACHES TO LITERATURE OF THE WAR}

Firstly, this article proposes an approach to the national construction of the story of the Falkland Islands. Secondly, it also analyzes the literature which deals with the Falklands war from three narrative periods: 1982-1989, 1990-2001 and 2002-2017. Periodization responds to different generations but also to the social processes that have accompanied the political and cultural transformation in Argentina. Finally, this article analyzes the most representative works of each period, in order to identify the main genres, plots and narrative conflicts that have emerged up to this moment.

KEYWORDS: Falkland Islands, war, Argentinian literature, historical memory, national narrative. 
“...algunos recordamos ese día en que Las Islas se habían vestido de blanco para nosotros y comprendimos lo que habían querido decirnos: que era más serio de lo que pensábamos, más definitivo y final: que estábamos casados con ellas".

(Carlos Gamerro, Las Islas)

Tres días después de la rendición de Argentina en la guerra de Malvinas, Rodolfo Fogwil acabó Los Pichiciegos, instaurando con su escritura un modo desacralizado y corrosivo de contar el conflicto. Desde ese momento, el goteo narrativo fue constante y las producciones culturales sobre la ofensiva fueron capaces de desafiar la falta de interés del discurso histórico, la negación de los gobiernos democráticos, la marginación de los excombatientes y el aparente olvido de la población. La literatura, en definitiva, asumió y resignificó la derrota y sus consecuencias.

El presente trabajo abordará, primero, la construcción y evolución del relato nacional en torno a las Islas. Segundo, se plantea un recorrido por la literatura sobre Malvinas desde 1982 hasta 2017, a partir del cual se propondrán tres momentos distintivos en la producción, establecidos a partir de la división generacional de los escritores, de los cambios sociales y de las características de los narradores y personajes. En la tercera parte se propone un análisis más detallado de las obras que se consideran claves en cada periodo. De la década de los ochenta: Los pichiciegos de Rodolfo Fogwill y A sus plantas rendido un león de Osvaldo Soriano. De la década de los noventa: Las Islas de Carlos Gamerro. Del siglo XXI: Dos veces junio y Ciencias Morales de Martín Kohan y Trasfondo de Patricia Ratto. En muchos casos hay alusiones a otros relatos que complementan el abordaje, y en alguna ocasión, como en Las Islas de Carlos Gamerro, la exposición se amplía respecto al resto de las novelas. La justificación, como podrá devengarse del análisis, responde a que se trata de una producción clave dentro de la constelación narrativa de Malvinas, ya que, además de encontrarse en el umbral del siglo XXI, es decir, entre el trabajo de la primera y la tercera generación, logra concentrar las principales angustias que la sociedad heredó de la guerra.

De este modo, teniendo en cuenta lo expuesto, el primer objetivo del presente artículo es actualizar la producción literaria en torno a la guerra de Malvinas, comprobando, de este modo, el relevo generacional en el racconto de la acción bélica. En segundo lugar, se busca discernir, por medio de los diferentes análisis, si la producción actual ha virado el enfoque sobre Malvinas 
y, si es así, ¿cuáles son los nuevos nudos narrativos a desentrañar? Finalmente, se pretende verificar si esta focalización de la guerra, lejos de ser una moda, 35 años después de la derrota, ha construido su propio nicho ficcional y su propio aparato crítico, afianzándose, de este modo, como tradición dentro de la novelística argentina.

\section{LA CONSTRUCCIÓN DE UN RELATO NACIONAL}

Cuando entre el 10 y el 11 de marzo de 2013 se llevó a cabo un referéndum entre los habitantes de las Falkland Islands sobre la soberanía de las Islas, el $99,83 \%$ votó que sí a la pregunta ¿desea que las islas Malvinas mantengan su estatus político actual como un territorio británico de ultramar? Sin embargo, e independientemente de los resultados, la contradicción es que las Malvinas para muchos de los argentinos fueron, son y seguirán siendo parte del territorio nacional. Lo son, porque desde la escuela primaria se contornean los mapas políticos hasta el final de la plataforma continental; porque se entona la "Marcha a las Malvinas" en los actos patrios, remarcando "ningún suelo más querido de la Patria en su extensión"; aunque la mayoría nunca haya pisado ese suelo ni vaya alguna vez a tocar esa tierra.

"Las Malvinas son argentinas" es un sintagma irreal, pues desde hace 180 años han sido ocupadas por los británicos, la guerra de 1982 se perdió, y el referéndum de treinta años después también. Pero las Islas en el imaginario del pueblo siguen siendo argentinas, lo son por su negación, por la connotación de la falta, y por la nostalgia del territorio usurpado trasmitida desde la fundación del gran relato nacional. Así, aunque el tema de la soberanía se reavivó con la guerra, la única en la que participó el país en el siglo XX, la insistencia sobre el territorio ha sido parte de la vida pública y política de Argentina prácticamente desde la ocupación británica. Este sentimiento de causa común al pueblo se tradujo en 1982 en un "consenso cívico-militar"

\footnotetext{
Retomando el trabajo de Luis Alberto Romero en La Argentina en la escuela. La idea de nación en los textos escolares, Vitullo analiza en Islas Imaginadas el sintagma "las Malvinas son argentinas" como una negación de los hechos que expresa el deseo de posesión del territorio. La autora lo equipara a la expresión "aparición con vida" como reclamo de la restitución de los desaparecidos, aun a sabiendas de la imposibilidad que encierra la frase.
} 
(Guber 13) que apoyó la acción bélica, aunque esta fuera abanderada por una dictadura.

Teniendo en cuenta que la consolidación de las naciones latinoamericanas se produjo con pocas décadas de diferencia del imperialismo colonial europeo del siglo XIX, resulta hasta previsible que el proceso de construcción de lo nacional en Argentina encontrara en Malvinas una de sus piezas fundamentales. Desde los primeros gobiernos de las Provincias Unidas del Río de la Plata, las Islas fueron consideradas parte integrante del territorio heredado de España según el uti possidetis juris ${ }^{2}$ de 1810, por el que los nuevos Estados asumieron la posesión de los territorios según la demarcación geopolítica legada por las antiguas potencias.

Si bien la idea de nación moderna presupone también el relato que alrededor de ella se instaura, en el caso argentino esa construcción ha estado reforzada por diversos símbolos y mitos heroicos que se han encargado de afianzar en la etapa escolar: el mapa, la bandera, el pasado breve pero glorioso implantado por medio de fechas, sucesos, lugares clave y héroes patrios. Como es de prever, las Islas no escapan a esta construcción, por el contrario, la escuela fue uno de los espacios privilegiados para la difusión de la causa de Malvinas. Por ello, "el discurso bélico de la época se hizo eco de una literatura escolar que concebía a las fronteras como zonas de choque y propiciaba la anexión simbólica de territorios a la nación" (Vitullo 38).

Es así como todo suma en la cimentación del imaginario de Malvinas: los escritos de José Hernández (1869) ${ }^{3}$, el periodo de "malvinización" de la década del 30, el proyecto de ley de 1934 presentado por el socialista Alfredo Palacios ${ }^{4}$ para traducir el libro de Paul Groussac sobre las Islas e

2 Del latín: como poseías [de acuerdo al derecho], poseerás. Simón Bolívar, al finalizar las guerras de independencia hispanoamericana, fue el primero en proponer durante el siglo XIX que los países hispanoamericanos emancipados conservasen las antiguas fronteras de las colonias del imperio español en América. Es decir, que los nuevos estados surgidos tendrían como fronteras las que le corresponderían de las colonias españolas en el año 1810 (Ramos 150).

Desde las páginas del diario El Río de la Plata culpa a los gobiernos de no tomar medidas diplomáticas luego de la usurpación, en la cual ve "como si se nos arrebatara un pedazo de nuestra carne" (Vitullo 32).

Alfredo Palacios (1878-1965) fue diputado y senador socialista. Luchó por los derechos de los trabajadores, las mujeres, los niños, los ancianos y los jóvenes. En este contexto intentó sumar la causa de Malvinas a los reclamos por la justicia social (Guber 76). 
introducirlo en las escuelas primarias (Guber); la creación de la "Junta de Recuperación de las Malvinas", que tenía el fin de reivindicar la soberanía y difundir la problemática a la población; el concurso poético-musical convocado por la "Junta...", en el que se eligió la composición de José Tieri y Carlos Obligado, Marcha de las Malvinas, como himno nostálgico del territorio perdido. Igualmente, la Constitución Nacional establece en la primera de las "Disposiciones transitorias" que "la Nación Argentina ratifica su legítima e imprescriptible soberanía sobre las Islas Malvinas, Georgias del Sur y Sandwich del Sur y los espacios marítimos e insulares correspondientes, por ser parte integrante del territorio nacional" (Constitución de la Nación Argentina).

Malvinas se ha constituido, de este modo, en la causa unificadora, la causa justa dirá Lamborghini en modo paródico, que en el imaginario nacional aglutinará más de cien años después a las voces oficiales y a las disidentes, a la derecha y a la izquierda, a víctimas y perpetradores. Julieta Vitullo argumenta:

La versión triunfalista de la guerra pretendió hacer del conflicto una epopeya, la gesta heroica de un pueblo encendido en la defensa de la nación. Los testimonios de los soldados, las cartas [...] los discursos oficiales y de los medios de comunicación dan cuenta de esta versión. [...] Todas se fundan en un discurso nacionalista elemental y no necesariamente ideológico (34).

En la misma dirección, Edgardo Esteban, excombatiente, explica en el prólogo a Las otras islas, que fue precisamente ese discurso común de apoyo a la guerra lo que impidió "asumir la derrota y debatir la utilización política de la causa Malvinas por parte de un gobierno de facto que venía desarrollando desde 1976 una política sistemática de terrorismo de Estado" (8). Aquellos que sobrevivieron, los héroes mutilados, tuvieron que superar la guerra, pero también la humillación del propio pueblo que antes los había arengado; así, al abandono del gobierno, a la traición de "los Padres de la Patria" hubo que sumarle la marginación social, sentimiento que los personajes ficcionales, como veremos en las páginas siguientes, han sabido trasmitir nítidamente. El narrador de Trasfondo, por ejemplo, desde un submarino-tumba, vuelve corpórea la marca de la vergüenza: "lo mejor hubiera sido estallar en mil pedazos y no volver, así seríamos víctimas o héroes, no esta evidencia viva de lo que no funciona, de lo que está mal, del fracaso" (Ratto 136). 


\section{EL FIN DE LA EPOPEYA Y EL NACIMIETO DE LA LITERATURA SOBRE LA GUERRA}

Dada la carga histórica que conllevaba el territorio de Malvinas y la euforia general con que se recibió la toma del territorio por parte de Gobierno Militar, en las décadas posteriores a la guerra no todos los discursos fueron capaces de abordar el trauma de la derrota. En este contexto fue la literatura y su constancia en el tema lo que impulsó las primeras representaciones del conflicto y erigió alternativas ficcionales para los vencidos. Elsa Drucaroff habla de "una mancha temática" que sigue sangrando, una marca especialmente productiva "no por frecuencia sino por calidad y persistencia" (Malvinas 18). Julieta Vitullo, por su parte, afirmará que "Malvinas es un malestar en la conciencia nacional al que el discurso político parece no poder enfrentarse pero la literatura sí" (16). Incluso quienes analizan el tema desde el otro lado del Atlántico, como María José Bruña y Guillermo Mira, también reparan en las posibilidades que contiene la ficción frente a la dificultad testimonial:

No es posible contar Malvinas desde el testimonio, desde la crónica histórica o periodística con el lenguaje sobrio, lúcido y ecuánime de Levi, con similar agudeza y profundidad de ideas. No es posible, tampoco, encontrar, totalmente, ese cierto alivio ético y hay que recurrir al aparato ficcional para decir por completo la pérdida y el horror (41).

Es decir, ante el enmudecimiento que provoca el campo de batalla, ante la pobreza de la experiencia que ya explicaba Walter Benjamin respecto a la Primera Guerra Mundial (112), frente a la imposibilidad de la palabra, la escritura ficcional producida tanto por excombatientes (Edgardo Esteban, Gustavo Caso Rosendi), como por la primera y la segunda generaciones que vivieron la contienda, se erige como un punto de fuga.

Profundizando en el diálogo transatlántico, aunque ahora con un cruce interpretativo entre la producción argentina sobre la guerra de Malvinas y la española sobre la Guerra Civil, Vicente Luis Mora abre como "puente" entre las relaciones literarias de ambos países la necesidad común de revisitar los conflictos bélicos por parte de las nuevas generaciones, urgencia en la que ahonda también la presente investigación. Luis Mora advierte que si bien es precisa una rehistorización, los narradores deben seguir teniendo en su horizonte la función de novelistas, y no confundirse con los historiadores, para ello 
no tienen que hacer de sus novelas una mera traslación historiográfica, periodística o testimonial de los períodos, sino encarnarlos, recuperarlos para el pensamiento y no para la hemeroteca, (...) toda la literatura española o argentina sobre un conflicto, el que sea, sólo tiene sentido si parte de la construcción de un conflicto interno, textual, caracterológico, estructural, estilístico, que sacuda la conciencia (232).

En el caso argentino, la "encarnación" de la guerra no solo ha sabido solventar aquello que el discurso histórico tardó en asumir, también ha presentado una riqueza en la construcción de narradores y en la multiplicidad de focalizaciones, géneros, formas y estilos. Además de mostrar esta diversidad, gran parte de la producción literaria sobre la guerra porta la capacidad de "sacudir la conciencia", es decir, la diégesis ficcional arrasa también con el amañado relato nacional, desarma la posibilidad de cualquier epopeya y deja en entredicho los conceptos de "patria", "nación" y "héroe". Martín Kohan lo explica magistralmente en El país de la guerra: "La literatura argentina cuenta la guerra de las Malvinas previa dinamitación de esos dos grandes pilares de sustento: la vibración de los tonos épicos y la fundamentación de los valores de la identidad nacional" (269). Kohan afirma esto como crítico, aunque como autor de Dos veces junio y Ciencias morales, él mismo ha puesto antes en práctica la escisión del relato nacional. De hecho, en ambas novelas, que serán retomadas en las próximas páginas, Malvinas es un sentimiento omnipresente, pero que no puede ser nombrado, tan solo aludido.

\section{ESCRIBIR LA GUERRA}

La respuesta de las letras a la guerra fue inmediata, comenzó a gestarse antes de que acabara la contienda. Entre las primeras manifestaciones poéticas se encuentra "Juan López y John Ward", publicada por Borges en el diario Clarín, en agosto de 1982: "Hubieran sido amigos, pero se vieron una sola vez cara a cara en unas islas demasiado famosas, y cada uno de los dos fue Caín, y cada uno, Abel” (Borges 28). Nahuel Santana, también desde la poesía, escribe "El mal vino", un juego de palabras con el que inaugura un espacio poético donde la violencia ya no solo es sobre los cuerpos sino también sobre la lengua, un nuevo lenguaje nace del castellano, uno fraguado en la muerte e interrumpido sucesivamente por el léxico de guerra y por la invasión del inglés. 
En la narrativa será Fogwill quien instaure el tema con Los pichiciegos. Esta novela, que tiene la particularidad de haber sido redactada en seis días y acabada tres después del rendimiento de Argentina ${ }^{5}$, ya sienta las bases sobre los modos de narrar el conflicto bélico, e incluso marca el pulso para una tipología de personajes que serán retomados con más detalle en las décadas posteriores: desertores, delatores, traidores, débiles, cobardes, incluso fantasmas, y una ristra de protagonistas que escapan dilapidando cualquier arquetipo heroico.

A modo de aproximación a la producción literaria propongo a continuación un listado de los principales cuentos, poemas, dramaturgias y novelas sobre la guerra de Malvinas, que han aparecido desde el conflicto y hasta el año 2017:

\begin{tabular}{|l|l|c|}
\hline AUTOR & OBRA & AÑO \\
\hline Rodolfo Fogwill (1941-2010) & Los pichiciegos & $1982^{6}$ \\
\hline Nahuel Santana (1950) & "El mal vino" & 1982 \\
\hline Jorge Luis Borges (1899-1986) & "Juan López y John Ward" & 1982 \\
\hline Carlos Gardini (1948-2017) & "Primera línea" & 1982 \\
\hline Osvaldo Lamborghini (1940-1985) & La causa justa & 1983 \\
\hline Griselda Gambaro (1928) & Del Sol naciente & 1984 \\
\hline Fernando López (1948) & Arde aún sobre los años & 1985 \\
\hline Jorge Luis Borges (1899-1986) & "Milonga del muerto" & 1985 \\
\hline Osvaldo Soriano (1943-1997) & A sus plantas rendido un león & 1986 \\
\hline Susana Théon (1935-1991) & $\begin{array}{l}\text { "Poema con traducción simultánea } \\
\text { Español-Español" }\end{array}$ & 1987 \\
\hline Néstor Perlongher (1949-1992) & "El informe Grossman" & $198 ?$ \\
\hline Martín Caparrós (1957) & El tercer cuerpo & 1990 \\
\hline Juan Forn (1959) & "Memorándum Almazán" & 1991 \\
\hline Rodrigo Fresán (1963) & "El aprendiz de brujo" (en Historia & 1991 \\
\hline Rodrigo Fresán (1963) & "La soberanía nacional"(en Historia & 1991 \\
\hline Carlos Feiling (1961-1997) & El agutina ) & 1992 \\
\hline Daniel Guebelrizada $(1956)$ & "El amor de Inglaterra" & 1992 \\
\hline
\end{tabular}

$5 \quad$ Así lo manifiesta Rodolfo Fogwill en la última página de la novela: "11-17 de junio de 1982" (156). El vertiginoso proceso de escritura ha sido retomado, igualmente, en las entrevistas en las que el autor se refiere a Los pichiciegos.

6 En este caso, teniendo en cuenta que la obra circuló con anterioridad a su publicación, se indica el año de escritura y no el de su salida al mercado, en 1983. 


\begin{tabular}{|c|c|c|}
\hline Daniel Guebel (1956) & $\begin{array}{l}\text { "Impresiones de un natural } \\
\text { nacionalista" }\end{array}$ & 1992 \\
\hline Marcelo Eckhardt (1972) & El desertor & 1992 \\
\hline Osvaldo Soriano (1943-1997) & "Otoño del 53" & 1993 \\
\hline Edgardo Esteban (1962) & Iluminados por el fuego & 1993 \\
\hline Daniel Ares (1956) & Banderas en los balcones & 1994 \\
\hline Jorge Stamadianos (s.f.) & Latas de cerveza en el Río de la Plata & 1995 \\
\hline Jorge Leyes (1963) & Bar Ada & 1997 \\
\hline Gustavo Nielsen (1962) & La flor azteca & 1997 \\
\hline Carlos Gamerro (1962) & Las Islas & 1998 \\
\hline Federico León (1975) & Museo Miguel Ángel Boezzio & 1998 \\
\hline Federico Andahazi (1963) & "El dolem" & 1999 \\
\hline Raúl Vieytes (1961) & Kelper & 1999 \\
\hline Vicente Zito Lema (1939) & Delirium teatro & 1999 \\
\hline Edgardo Russo (1949-2015) & Guerra conyugal & 2000 \\
\hline Martín Kohan (1967) & Dos veces junio & 2002 \\
\hline Martín Kohan (1967) & Ciencias morales & 2007 \\
\hline Roberto Herrscher (1962) & $\begin{array}{l}\text { Los viajes del Penélope. La historia } \\
\text { del barco más viejo de la Guerra } \\
\text { de Malvinas }\end{array}$ & 2007 \\
\hline Gustavo Caso Rosendi (1962) & Soldados & 2007 \\
\hline Patricio Pron (1975) & Una puta mierda & 2007 \\
\hline Sebastián Basualdo (1978) & Cuando te vi caer & 2009 \\
\hline Carlos Gamerro (1962) & $\begin{array}{l}\text { Las Islas (Adaptación a teatro de la } \\
\text { novela publicada en 1998) }\end{array}$ & 2011 \\
\hline Federico Lorenz (1970) & Fantasmas de Malvinas & 2011 \\
\hline Guillermo Orsi (1946) & Segunda Vida & 2011 \\
\hline Juan Guinot (1969) & 2022: la guerra del Gallo & 2012 \\
\hline Fabiana Daversa (1964) & La balsa de Malvina & 2012 \\
\hline Patricia Ratto (1962) & Trasfondo & 2012 \\
\hline Federico Lorenz (1970) & Montoneros o la ballena blanca & 2012 \\
\hline $\begin{array}{l}\text { Recopilación de cuentos de Marcelo } \\
\text { Birmajer, Liliana Bodoc, Pablo de } \\
\text { Santis, Juan Forn, Inés Garland, } \\
\text { Pablo Ramos, Eduardo Sacheri, } \\
\text { Patricia Suárez, Esteban Valentino. } \\
\text { Prólogo: Edgardo Esteban. }\end{array}$ & Las otras islas & 2012 \\
\hline Eduardo Belgrano Rawson (1943) & $\begin{array}{l}\text { Vamos fusilando mientras llega } \\
\text { la orden }\end{array}$ & 2013 \\
\hline Soledad Pereyra (1977) & Desmesura & 2013 \\
\hline Carlos Godoy (1983) & La construcción & 2014 \\
\hline Pablo Bilsky (1963) & "Hedor" & 2015 \\
\hline
\end{tabular}




\begin{tabular}{|l|l|l|}
\hline María Laura Riba (1965) & Un sapucay en la nieve & 2016 \\
\hline Juan Terranova (1975) & Puerto Belgrano & 2017 \\
\hline Sergio Olguín (1967) & 1982 & 2017 \\
\hline
\end{tabular}

Fig.1. Listado de principales obras literarias que aborda el conflicto de Malvinas ${ }^{7}$

A partir de los datos sobre las principales obras que se acercan a la guerra de Malvinas, queda en evidencia, por un lado, que la producción se ha mantenido constante desde 1982. En este punto, como es de prever, en los ciclos que se acercan a los aniversarios las publicaciones aumentan, aunque muy sutilmente. También cabe advertir la poca producción femenina en torno al tema, hasta el momento la respuesta de la ficción ha sido predominantemente masculina. Exceptuando los ejemplos de Griselda Gambaro y Susana Théon en los 80, la primera con una obra de teatro y la segunda con un poema. Para la novela sobre Malvinas escrita por mujeres hubo que esperar al siglo XXI. Así, con motivo del 30 aniversario de la guerra aparecen los textos de Fabiana Daversa y Patricia Ratto. Poco después los de Soledad Pereyra y María Laura Riba.

Igualmente, creo importante resaltar el cambio generacional entre los escritores de las diferentes décadas ${ }^{8}$. Para ello, parto de la división generacional que esboza Elsa Drucaroff (Los prisioneros 177-179) en torno a la última dictadura argentina (1976-1983). Esto es, la "generación de militancia", dividida a su vez en la "generación de mando" (escritores nacidos hasta la década del 40) y una generación más joven, que fue "testigo" tanto de la militancia de izquierda como de la violencia del terrorismo de Estado (nacidos en la década del 50). Y, finalmente, los narradores de postdictadura, que engloba tanto a aquellos que eran niños o adolescentes en el momento del golpe militar, como a los que nacen durante el "Proceso" o ya en democracia. Esta última generación es la que se identifica como la "Nueva Narrativa Argentina" (NNA) . Martín Kohan.

La presente lista recoge y amplía los textos mencionados por Julieta Vitullo y

Un acercamiento a la visión de las diferentes generaciones de Malvinas lo realiza Exequiel Svetliza.

La autora identifica a las dos generaciones de postdictadura con este nombre respondiendo a una continuidad temática. No obstante, el apelativo surge por parte de la segunda generación de postdictadura, a partir de las publicaciones de antologías de relatos que salen al mercado a partir del año 2004 (Drucaroff 183-185). 
Siguiendo esta secuencia y adaptándola a las necesidades propias de la literatura de Malvinas, sin afán de etiquetar pero sí de descubrir la evolución literaria, propongo tres focos ficcionales sobre la guerra: 1982-1989, 19902001, 2002-2017. El criterio para establecer la periodización tiene que ver con los cambios políticos y sociales, especialmente en cuanto a las políticas de derechos humanos. En cada etapa, considero, hay relatos sobre la guerra que acompañan la evolución social, desde la imposibilidad de asumir la derrota en los primeros años, a la denuncia de las políticas de olvido e invisibilización de los excombatientes en los 90, a una evolución en la memoria colectiva de la guerra que se concreta, en 2017, con la identificación de los soldados enterrados como $\mathrm{NN}^{10}$ en las Islas ${ }^{11}$.

\section{2-1989. LOS DESERTORES}

Esta etapa coincide con las dos primeras generaciones propuestas por Drucaroff, es decir, aquellos que nacen hasta la década del 50. Es la generación de escritores consagrados, o al menos ya maduros intelectualmente en el momento del enfrentamiento bélico. Esta generación escribe en los 80, los años de la guerra proclamada y la guerra perdida. Publican en un momento donde los cambios sociales son vertiginosos: la década del fin de la dictadura, la llegada de la democracia y el avance en derechos humanos con medidas como la Comisión Nacional sobre la Desaparición de Personas (CONADEP) (1983), el Informe de la Comisión Nacional sobre la Desaparición de Personas. Nunca más (1984) y el juicio a las Juntas Militares (1985). También presencian al avance de la impunidad con las leyes de Obediencia Debida y Punto Final (1987) y los primeros indultos (1989). En este periodo destacan, dentro de las lecturas

10 Son las iniciales de la expresión latina nomen nescio, que literalmente significa "desconozco el nombre". Se utiliza para hacer referencia a aquellos cuerpos que se desconoce la identidad.

11 El 1 de diciembre de 2017 se anunció la identificación de 88 soldados que estaban enterrados como NN, con la leyenda "Soldado argentino solo conocido por Dios". Las negociaciones para la identificación comenzaron en 2012, por iniciativa del gobierno de Cristina Fernández de Kirchner. Información disponible en CNN: http://cnnespanol.cnn. com/2017/12/01/malvinas-cuerpos-soldados-muertos-identifican-cementerio-darwin/; Infobae: https://www.infobae.com/sociedad/2017/06/18/malvinas-manana-comienza-la-identificacionde-los-restos-de-soldados-argentinos-enterrados-como-nn-en-el-cementerio-de-darwin/ 
que propongo, Los pichiciegos y A sus plantas rendido un león. Entre las dos abarcan el efecto expansivo de la guerra, dentro y fuera de las fronteras argentinas, y sientan las bases del "contrarrelato de la guerra de Malvinas" (Kohan 272). El texto de Fogwill exhibe por primera vez la voz ficcional de un soldado, Quiquito (Enrique), que reconstruye lo que sucedió en las Islas. Este personaje, el único sobreviviente de los pichis, relata frente a un escritor la historia de los desertores. El lector asiste al mecanografiado de las voces del sobreviviente y del entrevistador, registradas en casetes (Fogwill 100, 103, 131), es decir, inventariadas, reproducidas, quizás corregidas. De este narrador autoficcional que pregunta, interrumpe y guía el recuerdo de Quiquito se nos cuenta que tiene publicado un libro anterior, Música japonesa (Fogwill 113), título que coincide con el segundo libro de cuentos de Rodolfo Fogwill. De este modo, Los pichiciegos reconstruye no solamente los sucesos en el territorio de ultramar sino también la elaboración posterior del testimonio, hecho fundamental para la construcción social del relato de la guerra. Tal como indica Tennenini, "es una novela que relata el pasaje del testimonio al archivo, a saber el momento en que la experiencia individual, al devenir colectiva, glosa el discurso político y plantea el problema de la elaboración crítica de la historia oficial" (§ 30$)$. No obstante, a partir de esta cita, cabría apuntar que esa elaboración crítica del testimonio que propone Fogwill se forja también desde la invención, ya que el narrador autoficcional resignificará lo oído a partir de una ficción, no a partir de una biografía:

A la mañana siguiente le mostré las primeras ciento doce páginas del libro mal tipiadas por Lidia y él las miró y preguntó si podía quedarse con una copia. Dije que sí. Por entonces él estaba leyendo Música Japonesa y había dicho que le gustaba.

-Ustedes -dijo- son como las minas: lo que más les gusta es que a los otros les guste... (113).

Otro nudo narrativo instaurado por Fogwill y que no ha cesado de ser abordado es el carácter picaresco de los soldados. La identificación con los desertores se desprende desde el título pero, en caso de que el lector no llegue a la asociación, en la novela se concretan las cualidades de los combatientes con un tipo de armadillo autóctono de Argentina: "el pichi es un bicho que vive bajo tierra. Hace cuevas. Tiene cáscara dura -una caparazón- y no ve" (27). Estos "topos", para recurrir a un término análogo acuñado por Torbado y Leguineche (18) para referirse a los republicanos que permanecieron escondidos durante la dictadura franquista, solo desean 
que acabe la guerra, sin importar el resultado. Para ellos, el valor está en no dejarse matar, en sobrevivir. Así, sus ambiciones se contraponen a la epopeya que podría gestarse en una batalla, de hecho sus anhelos son más próximos a un imaginario de bienestar cultivado en el cine: "ser un malvinero y tener una de esas estancias enormes. Vivir ahí, tener mujer, perro, todos rubios y fumar en pipa y mirar el pasto -cuando haya- sin que me vengan a joder los británicos ni los argentinos" (Fogwill 139).

Siguiendo con la caracterización, los pichis tampoco destacan por la lealtad, prueba de ello es que tienen un mercado negro con los campamentos enemigos, intercambian víveres, provisiones, incluso información y rehenes de su propio ejército. También colaboran con los ataques británicos y festejan la muerte de los miembros de la marina argentina (47). La falta de código, sin embargo, se manifiesta como consecuencia del accionar de sus superiores, representados por las mismas fuerzas represivas del autodenominado Proceso de Reorganización Nacional ${ }^{12}$. La presencia de torturadores en las islas, en tanto extensión de los Centros Clandestinos de Detención en el campo de batalla, es vislumbrada por Fogwill casi a la vez que sucedían los hechos. En una de las conversaciones que nos repone Quiquito, surge la discusión sobre los vuelos de la muerte y la vinculación de uno de los Sargentos en los operativos:

-Videla dicen que mató quince mil - dijo uno, el puntano. [...]

-No sé -dudada Viterbo-, mataron muchos, ahora que los hayan fusilado... no sé.

[...] -Yo sentí que los tiraban al río desde aviones.

[...] -Yo también lo había oído decir que los largaban al río desde los aviones, desde doce mil metros [...]

[...] - ¡Lástima que no esté el Sargento! Él sabía eso.

¡Y cómo no iba a saber eso si él trabajó de eso! ¡Si tenía una medalla del Operativo Independencia! -dijo Acosta (49-50).

En este diálogo queda corroborada la utilización del mismo "personal" para uno y otro fin. Así, en esta remisión, el horror vivido en la dictadura se extiende también a las Islas, de modo que los muertos de la guerra y los

12 Este es el eufemismo utilizado por los militares golpistas para denominar a la última dictadura cívico militar en Argentina, cuyo periodo se extiende del 24 de marzo de 1976 al 10 de diciembre de 1983. 
desaparecidos en la península se confunden. La diferencia será que con la vuelta a la democracia, los desaparecidos ocuparon un sitio en el discurso político y en las reivindicaciones de los organismos de derechos humanos; los excombatientes, en cambio, siguieron "tras el manto de neblina"13, perdidos junto a las Islas.

Igualmente, en este relato inaugural, la acción de los combatientes es desplazada de lo heroico a lo paródico. El mito crece, sí, pero no como épica. La leyenda de los soldados escondidos trasciende entre las tropas y son alabados no por sus hazañas bélicas sino por hacer huecos en la tierra. Ocultarse los convierte, a ojos del resto de los personajes, en vivos. "Decían que había como mil pichis escondidos en la tierra, jenterrados! Que tenían de todo: comida, de todo. Muchos decían tener ganas de hacerse pichis cada vez que se venían los Harrier soltando cohetes" (Fogwill 29).

Osvaldo Soriano, por su parte, se aleja del territorio nacional y desarrolla las peripecias de $A$ sus plantas rendido un león en un imaginario imperio centroafricano (Bongwutsi), donde reside un fingido cónsul argentino, Bertoldi. Con la construcción de este personaje, Soriano introduce varios conflictos, en primer lugar, el de la identidad falsa y, por ende, la legitimidad de los actos de quien usurpa un cargo público. Por otro, el impacto de la guerra fuera del territorio nacional, algo que será retomado en 1991 por los cuentos "Aprendiz de brujo" (Fresán) y "Memorándum Almazán” (Forn).

En esta novela, bañada de ironía, se potencia la idea de un patriotismo kamikaze. Con similar desatino, irracionalidad e ilegitimidad que se declaraba la guerra dentro de las fronteras argentinas, en el momento en que la noticia llega a Bongwutsi, Bertoldi decide plantar la bandera albiceleste en la embajada británica: "Se preguntaba cómo responder al embajador británico, y aunque tenía atolondrado el pensamiento, lo ganó un incontenible deseo de llevar la enseña de la patria hasta la zona de exclusión y plantarla allí, como una estaca en el arrogante corazón de Mister Burnett" (Soriano 33). El trazo de este esperpéntico cónsul, cuya creación se cimenta en la farsa, tiñe la obra de Soriano de una acérrima crítica al patriotismo que desencadenó la guerra, pero también, como señala Kohan, con este movimiento se resquebrajan las bases de la identidad nacional (El país de la guerra 277).

13 Recupero en esta imagen el verso con el que comienza la Marcha de Malvinas: "Tras su manto de neblinas, / no las hemos de olvidar./ ¡Las Malvinas, Argentinas!,/ clama el viento y ruge el mar". 


\section{0-2001. LA VUELTA A LAS ISLAS}

El segundo foco de escrituras de la guerra propuesto se sitúa en dos fechas políticamente complejas. La primera, 1990, coincide con el afianzamiento de la era menemista ${ }^{14}$ y la ratificación de la impunidad por medio de una segunda oleada de indultos. Se cierra en 2001 con el estallido social, conocido como "el argentinazo" o "el cacerolazo". Durante estos 11 años aparecen los relatos de quienes nacieron mayoritariamente en la década de los $50 \mathrm{y}$ hasta mediados de los 60, con excepción de Marcelo Eckhardt y Federico León, que son de los 70. Aquí se incluye a la generación de "los chicos de la guerra", los nacidos entre 1962 y 1963. Los escritores de estos años tienen la misma edad que los conscriptos que fueron al combate mientras cumplían el Servicio Militar obligatorio. No es un dato menor, ya que representan un gran porcentaje de quienes ficcionalizan el tema: Rodrigo Fresán, Jorge Leyes, Gustavo Nielsen, Carlos Gamerro, Federico Andahazi, Roberto Herrscher, Pablo Bilsky y Patricia Ratto. Se suman los excombatientes Edgardo Esteban y Gustavo Caso Rosendi.

Este segundo ciclo propuesto se inicia con la publicación de El tercer cuerpo de Martín Caparrós, una novela en clave policial que funciona como bisagra entre los 80 y los 90: manifiesta el temor a la pérdida de la democracia pero también la ebullición social. Asimismo, logra anticiparse a lo que se corroborará en el gobierno de Carlos Menem, por un lado, la corrupción, las privatizaciones, la "pizza con champagne", el tráfico de drogas; por el otro, la miseria, el hambre, la desocupación, las huelgas, la desprotección de los colectivos más vulnerables. Sigue dominando la diégesis narrativa la preeminencia de la violencia y la construcción de personajes antiheroicos, como el investigador Matías Jáuregui, cocainómano y movido más por intereses personales que por una ética humanitaria. Esta novela también devela la presencia de los mecanismos dictatoriales en democracia e indaga en las consecuencias del olvido del pasado traumático.

14 El periodo conocido como "menemismo" hace referencia a las presidencias de Carlos Saúl Menem (1989-1999). La época se caracterizó por el olvido de los crímenes de lesa humanidad y por las escasas referencias al pasado. La bonanza económica, las privatizaciones, el espectáculo mediático, la corrupción y el indulto a los militares alejaron la mirada de cualquier suceso traumático para trasladarla a los valores más efímeros. 
No obstante, a mi entender, la obra más representativa de esta etapa y la más global que se ha escrito hasta el momento sobre el conflicto de Malvinas es Las Islas, de Carlos Gamerro. Este texto, al borde del milenio, permite una visión panorámica de los intereses que hubo detrás de la contienda y, sobre todo, de las consecuencias del olvido en el que cayeron los excombatientes. La novela acentúa su carácter deconstructivo de la epopeya bélica, y es exhaustiva en su sátira política y social, no solo en referencia a la dictadura, también respecto al momento de escritura. A la vez, en sus más de 600 páginas realiza un complejo trazo de los personajes, donde es capaz de ahondar en la psicología de víctimas y perpetradores. Gamerro marca un modo de narrar que, aunque deudor de los autores anteriores en el mecanismo paródico, el contrarrelato de la identidad nacional y en el tratamiento picaresco, se vigoriza con la inclusión de nuevas problemáticas, como es el caso del retorno (imaginario) a las islas por parte de los excombatientes.

Las Islas recrea la existencia de un exsoldado, Felipe Félix, una década después del conflicto. El texto tiene un doble tiempo y espacio, por un lado, el pasado en el campo de batalla, al que Felipe regresa por medio de las alucinaciones, los sueños y los recuerdos. Por otro lado, el presente en Buenos Aires, donde trascurre la acción principal. Como en la novela de Caparrós, Gamerro se hace eco de la sociedad del desencanto de los 90 y de la vulnerabilidad de los excombatientes. De esta manera, Felipe Félix figura el trauma de la guerra no en sentido general sino en uno particular que le otorga Malvinas: jóvenes sin experiencias, sin equipos y sin comida; con igual miedo al frío de las Islas y las bombas de los británicos que a los superiores argentinos, muchos de ellos vinculados a la dictadura, que torturaban y causaban bajas en su propio ejército. Además de esta línea, que ya había sido esbozada en la etapa anterior, Gamerro introduce de manera novedosa la huella que la derrota ha dejado en los "regresados": la vergüenza, el silencio, la falta de trabajo, las adicciones, la locura, los suicidios y la necesidad de volver al lugar de la tragedia. El epígrafe que encabeza este artículo explica ese nudo con el horror, el "casamiento" de los combatientes con las islas, el vínculo indisoluble que escenifica el quiebre en la experiencia. No hay retorno para "los chicos de la guerra", en la novela el pacto suicida arrasa, como una infección, a los sobrevivientes. Y se propaga, incluso hasta quienes no han conocido las ínsulas. Frente a uno de los médicos del psiquiátrico El Borda, Felipe Félix explica cómo su falta se extiende "como los chagásicos", e incluye a su interlocutor en la nostalgia del territorio, a los que no fueron pero que aún así deberán cargar con la memoria colectiva del trauma: 
Todos soñamos con volver. Es difícil de explicar. Yo no volvería ni loco. Pero sueño con volver -hice una pausa-.

Ustedes también.

- ¿Nosotros?

-Los que nunca estuvieron (412-413).

La idea de extensión de la falta hacia aquellos que no estuvieron, incluso hacia las nuevas generaciones, es recuperada por Juan Guinot en 2022. La guerra del gallo, novela a la que me referiré en el próximo apartado.

En su racconto, Las Islas se nutre de las características del relato policial. Un empresario nazi, Tamerlán, propone a Felipe Félix seguir las pistas de los testigos de un asesinato cometido por su propio hijo. La demanda no está motivada por el esclarecimiento del crimen, sino por los intereses expansionistas del millonario, que tiene el propósito de lograr una Tercera Fundación de Buenos Aires. De este modo, la historia épica de la nación es desarmada desde una hipérbole que la ridiculiza. En 1994, Blanco, Imperatore y Kohan ya reparaban en la deconstrucción que las ficciones operaban sobre el gran relato nacional, para ellos, este modo de contar no procedía de una superación por medio de los valores universales, sino más bien en una desarticulación por degradación, ya que

lo que la destrucción pone en funcionamiento es una lógica que ataca desde el exterior del sistema en cuestión, su objetivo es la superación y el reemplazo de ese otro sistema, por eso lo bombardea, pero no lo dinamita. [...] El Relato Argentino no va a ser destruido por valores superiores, sino deconstruido mediante la utilización de sus mismos principios, pero boicoteados en su esencia, corrompidos en su prestigio (Blanco et al. 83).

La novela de Gamerro llega poco después de este estudio, pero va al límite la deconstrucción de ese relato nacional. Lo hace desde muchos flancos narrativos, uno de ellos es la propuesta de creación de la Asociación Virreinal Argentina, cuyo objetivo es restaurar las fronteras nacionales según los límites históricos, es decir, "reconquistar Bolivia, Paraguay y Uruguay e invadir Chile y Brasil" (52), aunque, mientras llegan los fondos se encargan de reunir a los veteranos y dar cursos de historia nacional, política nacional y todas las disciplinas que contengan el adjetivo "nacional". La búsqueda constante de la identidad, que marcó Argentina desde su constitución como tal, aquí estalla por la parodia. No obstante, este recurso, también pone en 
evidencia la estrategia de manipulación de la opinión pública y la utilización de la gesta nacional como excusa para los intereses del gobierno de facto.

La Argentina mitificada del pasado, la que se instauró desde la Revolución de mayo (1810) y la posterior Independencia (1816) sigue apareciendo como ideario nacional, en esta cosmovisión la recuperación de las Islas se eleva como estandarte de éxito para futuras empresas. Citatorio, el profesor de la Asociación Virreinal Argentina, exagera el sentimiento glorioso y pone en la hazaña de recuperación el futuro del país:

La Argentina es una pija parada lista para procrear, y las Malvinas son sus pelotas. ¡Cuando las recuperemos volverá la fertilidad a nuestras tierras, y seremos una gran nación como soñaron nuestros próceres! ¡Un país potente! [...] Desde Las Islas recuperadas, un sol patrio de grandeza inimaginable marcará el nacimiento del día en que la ex colonia se convierta en la Argentina potencia que todos anhelamos! (58-59).

Esta disertación hiperbolizada caricaturiza también el discurso político-militar de la dictadura. Basta escuchar las palabras de Leopoldo Galtieri ${ }^{15}$, antes y después de la guerra, donde las evocaciones a la contienda son tratadas como "un acto argentino" justificado en un elemental sentimiento de argentinidad. El discurso del 2 de abril de $1982^{16}$, ovacionado en la Plaza de Mayo, habla de Malvinas como un comienzo, la recuperación se traslada al pueblo y se justifica en el orgullo y la dignidad.

No hemos hecho otra cosa que interpretar el sentimiento del pueblo argentino [...] Recién hemos comenzado con la actitud de recuperar las Malvinas y toda su zona de influencia y ya flamea la bandera argentina en nuestras Islas, que la comunidad internacional y nuestros adversarios circunstanciales de hoy comprendan cuál es la voluntad argentina. Aceptaremos el dialogo después de esta acción de fuerza pero en el convencimiento que la dignidad y el orgullo nacional deben ser mantenidos a toda costa y a cualquier precio (Galtieri).

16 El 2 de abril de 1982 se considera el día del inicio de la guerra, ya que es la fecha del desembarco argentino en las islas. 
La sentencia de recuperación de las Islas, aun luego del fracaso, será el fundamento para muchas ficciones, de este modo, si bien Las Islas de Gamerro lanza la piedra de la reconquista postbélica, la redención del territorio nacional retornará como leitmotiv en varias de las sucesivas representaciones. No de manera aleatoria, en el año 2000 José Luis Márquez presenta la película Fuckland, donde la estrategia de reposición territorial es tan desatinada como la de 1982. Aquí, el plan consiste en hacer una reproducción selectiva. Es la historia de Fabian Stratas, que viaja a las Islas con el objetivo de embarazar a las mujeres nativas de origen británico, su propósito es repoblar el territorio con descendientes argentinos. Las cuentas son las siguientes: si 500 argentinos hacen lo mismo cada año, en menos de 20 años la mitad de la población de las Islas será de ascendencia argentina. A pesar de lo innovadora que parece la idea, el germen de la repoblación por fecundación ya estaba en la ficción de Gamerro, "El diario del mayor X" ${ }^{17}$ reza: "sus mujeres incuban nuestros embriones clonados en su vientre" (479).

Tal como se comprueba con el personaje de Felipe Félix, e incluso en textos de la etapa anterior, como "Primera Línea" de Gardini, haber estado en la guerra de Malvinas es haberse quedado para siempre en el momento de la separación de ese territorio que comenzaba a idealizarse cual tierra prometida, es llevarse consigo la separación de la región que comienza a ser, a la vez, ausencia en el propio cuerpo -el simbólico de la nación pero también el físico, a causa de las mutilaciones-. Julieta Vitullo acude a la noción de "la épica ausente" (25), con ello refiere a todo lo que se evoca con la acepción: falta, vacío, carencia, pero también desaparición, huida, retirada. Así, la representación que se ha hecho de las Islas ha dado entidad a una posesión imaginaria que, en el caso del protagonista de Las Islas es llevada al extremo y convertida en una poética de la pérdida. La ausencia excede el lenguaje y se manifiesta en la propia carne. El cuerpo de Felipe Félix expele, suda, vomita, llora, al mismo tiempo recupera cíclicamente la tragedia: desde el fragmento de casco que le quedó incrustado en la cabeza, a la ingestión de drogas alucinógenas que lo remiten al área usurpada, hasta la recreación de la guerra por medio de la realidad virtual de un videojuego

17 En la ficción de Gamerro, el mayor X, seudónimo de Antonio Cuervo, representa a los militares implicados en las desapariciones durante la dictadura argentina y que luego fueron enviados a la guerra. Para un análisis detallado del diario en el que se reponen diferentes lecturas e intertextualidades, véase el artículo de Laura Destéfanis. 
donde los veteranos pueden revivir una y otra vez la derrota o, en algunos casos, tener una victoria que jamás sucedió. Félix desaparece de la linealidad del relato para retornar a las Islas. El círculo se repite compulsivamente diez años después. Su alternativa no es solamente poseerlas sino ser ellas, diluirse en su tierra blanca y yerma:

Dejamos un espacio preciso cuando nos fuimos, pero allá cambiamos de forma, y al volver ya no encajábamos, por más vueltas que nos dieran; en el rompecabezas. Volvimos diez mil iluminados, locos, profetas, malditos, y ahí andamos, sueltos por las cuatro puntas del país, hablando un idioma que nadie entiende, haciendo como que trabajamos, jugamos al fútbol, cogemos, pero nunca del todo, en algún lugar sabiendo siempre que algo nuestro valioso e indefinible quedó enterrado allá. En sueños, al menos, todos volvemos a buscarlo. ¿Entendés? No es el criminal el que vuelve al lugar del crimen. Es la víctima, bajo la tiránica esperanza de cambiar ese resultado injusto que la dañó. [...] No es verdad que hubo sobrevivientes. En el corazón de cada uno hay dos pedazos arrancados, y cada mordisco tiene la forma exacta de Las Islas $\left[{ }^{18}\right]$. Tratamos de llenarlos con las cosas de acá, pero es como taparlos con estopa (413-414).

La idea de fusión con el territorio y de herencia abarca toda la novela, no solo por medio del personaje de Félix; Temerlán dice respecto a su imperio: "todo el edificio es una mera prolongación multiplicada de mi propio cuerpo" (33). Las hijas de Gloria y su torturador, Arturo Cuervo, se llaman Malvina y Soledad y "parecen pingüinos" (289), como si fueran engendradas por las mismas Islas para que la marca del territorio se propague, aun en el Continente. por Daniel Casabé y Edgardo Dieleke. El film recupera este fragmento de la obra de Gamerro y parlamentos de otras ficciones sobre Malvinas. Lo protagoniza, no por azar, Julieta Vittulo que cuenta a través de dos viajes, en 2006 y 2010, su relación con las Islas como investigadora. En el trayecto de la filmación se encuentra con dos excombatientes, que entran en la trama del documental, como testigos y como protagonistas de la historia traumática del pasado y del presente. 


\section{2-2017. LA GUERRA DESDE EL SIGLO XXI}

El tercer foco narrativo surge a la par que se apuntala la Nueva Narrativa Argentina: con el cambio de milenio, pero sobre todo, estimulado, en sus inicios, por una gran crisis económica, política e ideológica, y consolidado con la vuelta a las políticas de derechos humanos a partir de la presidencia de Néstor Kirchner (2003-2007) y Cristina Fernández (2007-2015). Este tercer momento ensancha las posibilidades narrativas, no solamente por la evidente renovación generacional, ya que quienes escriben han nacido entre 1962 y 1983 , con excepción de las publicaciones de Guillermo Orsi (1946) y de Eduardo Rawson (1943), también porque la cocina de las producciones se efectúa en la era de la comunicación. El predominio de las nuevas tecnologías influye en el acceso a la información sobre el conflicto, en el proceso de construcción de las tramas y en la difusión de las producciones, que ahora llegan a un público más diverso por medio de las redes sociales. En esta época también se afianza el tratamiento de la guerra desde diversos géneros, con especial predilección por la novela de investigación y el acercamiento fantástico. Ambas presentes desde los primeros relatos, aunque ahora más extendidas y con mayor frecuencia. Los lugares de la narración también se amplían, las tramas siguen transcurriendo en diferentes espacios de la geografía argentina, en las islas o en el extranjero, pero también se extienden a otros sitios ligados a la acción bélica como son los submarinos (Trasfondo, de Patricia Ratto) o los barcos (Puerto Belgrano, de Juan Terranova).

Por otro lado, a los anteriores enfoques de quienes vivieron la guerra con una mirada adulta o iniciática, ya sea en el campo de batalla o por medio de las noticias, se agrega la perspectiva de quienes recibieron la noticia del conflicto siendo niños. De este modo, el trauma comienza a ser contado como herencia, tal es el caso de 2022. La guerra del gallo, de Juan Guinot y La balsa de Malvina, de Fabiana Daversa. La primera con la perspectiva de un no excombatiente y la segunda con la visión de la hija de un veterano.

Me centraré brevemente en la propuesta de Juan Guinot. En su obra, el personaje que debe lidiar con la derrota y con el hueco que han dejado las Islas es aggiornado y se presentará como un no-ex-combatiente de Malvinas, Masi. El protagonista recuerda su infancia mezclada con las noticias de la guerra, y toma para sí la misión patriótica. A la herida de la pérdida se suma la imposibilidad de luchar por el territorio a causa de la edad, de manera que cuarenta años después (2022), con Malvinas aún sangrando en su costado, 
decide conquistar el Peñón de Gibraltar. Así, transforma la causa Malvinas en una lucha universal contra los vestigios de las potencias colonialistas.

Una de las características que se subrayaron en la novela de Carlos Gamerro fue la sensación de los personajes de haberse anclado en el momento de la guerra. Este efecto de dilación interminable también se hace tangible en Trasfondo, de Patricia Ratto. En este texto asistimos a la voz de un narrador fantasma que no logra recordar y se encuentra detenido en la niebla densa que envuelve a un submarino. Todo lo que narra entra en un espiral de tiempo intangible, que otorga un carácter espectral a los personajes, los vuelve de un "blanco verdoso" (Ratto 114). En la obra, la asfixia de lo que se oculta en el fondo (la derrota, la muerte) cala también en una prosa opresiva. La mayoría de las imágenes o bien son episodios de olvido, o bien son una acumulación de repeticiones (las botas, las sábanas, el frasco de conservas, el libro). "Es como si la memoria se me estuviera llenando de agujeros [...] como si el bicho taladro estuviera por dentro devorándome mis recuerdos, lenta pero contantemente, hasta dejarme vacío, puro presente que tarde o temprano va a ser también devorado" (68-69).

El constante murmullo de Ortega, el marino-fantasma, tiene como fin la aceptación de su nueva condición. No hay acción ni datos novedosos en la novela, casi todo es espera: "Nos quedamos aquí, adentro, nuestro único lugar posible, esperando. Esperar es la sola maldita cosa que podemos hacer" (85). En cuanto a las Islas, nadie puede visualizarlas, como en la historia argentina, son siempre inaprensibles. Los marinos de Trasfondo nunca llegan a ellas: "Todavía no hemos podido verlas, nadie de la tripulación las vio, ni siquiera el comandante por el periscopio" (97). Las Islas son relato, ficción. Así, la guerra, la muerte y la derrota se construyen sobre el imaginario de ese territorio que nunca nadie ha pisado.

Por otro lado, uno de los autores de vital importancia en la nueva narrativa sobre Malvinas es Martín Kohan, que tanto en Dos veces junio como en Ciencias Morales ha dado continuidad a la creación de situaciones que rememoran la contienda, aunque sus alusiones transcurren desde el orden de lo implícito. Ciencias Morales sitúa su locus dentro del Colegio Nacional Buenos Aires, pero allí la guerra se reprime hasta que llega la derrota. El desplazamiento del texto es hacia el control disciplinario de la escuela, no por azar, lugar por excelencia en la construcción del imaginario de lo nacional. Aunque el tiempo del relato coincide con el tiempo de la guerra, esta es silenciada, solo aparece al final, en las pesadillas de María Teresa, cuando sueña con su hermano flotando, boca arriba, en el océano. Una imagen que 
retoma años después Patricia Ratto para describir la muerte de un soldado de Trasfondo. El hermano de María Teresa nunca llega a Malvinas, pasa toda la novela esperando y enviando postales a su familia. Sin embargo, aun sin ver el horror, el léxico seleccionado en Ciencias morales remite al miedo, al encierro, a la guerra. Es un ejemplo de contención absoluta (Vitullo 108). La premura de la muerte es presagio cifrado, tanto la de las Islas como la de Buenos Aires, que por momentos parece deshabitada, dispuesta también para ser arrasada por una bomba:

La calle luce tranquila. Demasiado tranquila, a decir verdad: es eso lo que tiene de extraña. Es la hora que corresponde al más intenso movimiento urbano y sin embargo aquí, en pleno centro, los autos escasean. Los peatones que ve pasar le parecen a María Teresa recién salidos de un sótano, como si se estuvieran trasladando de un refugio a otro refugio por las calles de una ciudad sometida a un ataque aéreo (Ciencias morales 36).

A la población oculta bajo tierra, como los pichiciegos, como los topos, se agrega otro claustro, el de María Teresa, que espera durante horas en un retrete del baño de hombres para "patrullar" a los alumnos. Pero aquí, esconderse dejará de tener el sentido último de la salvación, como antes veíamos en Los pichiciegos, y se convertirá en instrumento de vigilancia: "ella está mostrando en cambio un gran atrevimiento en este juego de espionaje que su tarea de celadora le ha deparado" (36).

En Dos veces junio, por su parte, el foco de la narración recae en un soldado que colabora con la dictadura, con él asistimos a la voz de los verdugos. La acción sucede durante dos derrotas. La primera en junio de 1978, coincide con el Mundial de Fútbol, la noche del partido que Argentina pierde contra Italia; la segunda, en junio de 1982, con el fracaso bélico. En ninguna de las dos partes se menciona Malvinas como territorio o en referencia a la guerra. Se nombra solo para indicar que la llamada del doctor Padilla "procedía de Malvinas, del Centro Malvinas, o sea de Quilmes" (Dos veces junio 41). Es decir, el imaginario de Malvinas es desplazado a la nomenclatura de un edificio donde funcionó un Centro Clandestino de Detención ${ }^{19}$.

19 Este CCD funcionó entre 1975 y 1979, era conocido como "chupadero de Malvinas" o "pozo de Quilmes". 
Como en Ciencias Morales, en Dos veces junio también se presiente la guerra, pero ahora serán los ejemplos del doctor Mesiano los que la presagien. Uno de estos se enuncia a la salida de un prostíbulo, cuando el médico reflexiona sobre el cuerpo de los soldados, de los enfermos y de las prostitutas:

\begin{abstract}
¿Qué puta no sabe que su cuerpo no es suyo? [...] Una puta entiende que su propio cuerpo no le pertenece, o por lo menos, que no le pertenece del todo. El enfermo terminal consigue, aunque muy por otro camino, arribar a esa misma certeza. [...] De alguna manera lograban una prodigiosa afinidad con lo que pasa en una guerra. Porque en una guerra los cuerpos ya tampoco son de nadie: son pura entrega, son puro darse a una bandera y a una causa. Así razonaba el doctor Mesiano: cuando en la guerra se acciona sobre un cuerpo, se está accionando sobre algo que ya no le pertenece a nadie. De ahí su interés por las putas de Vietnam, que habían llegado a ser, a un mismo tiempo, y maravillosamente, prostitutas, enfermas terminales, instrumentos de guerra (Dos veces junio 120).
\end{abstract}

Estos cuerpos, que no solo son los de enemigos extranjeros sino también los de los propios ciudadanos, son detenidos y asesinados por el Estado en el primer junio, y enviados a la guerra en el segundo. En ambos casos, el destino es la desaparición. "Hay que pensar que un prisionero ya es un muerto. [...] Hay que pensar que ya está muerto desde el momento en que cayó en poder del enemigo" (115). En el segundo junio, el subalterno lee en el listado de los "caídos en combate" (161-162) el nombre de Sergio Mesiano, hijo de su antiguo superior, y decide visitar al médico para darle el pésame. El conscripto lo encuentra en la casa de su hermana, compartiendo un asado al que lo invitan a unirse. La escena desborda banalidad, la única que parece sufrir la muerte de Sergio es su madre, Lidia, que según dicen está loca, recluida en una habitación. Aquí la guerra de Malvinas, una vez más, se silencia. Omisión que no impide que la presencia fantasmal del dolor siga perturbando, como un miembro amputado, a los personajes y a la narración.

\title{
CONCLUSIONES
}

Malvinas es un archipiélago, un nombre sagrado, una guerra, un territorio, tierra, mar, montañas, nieve, es un ideal, un hueco, un sueño. Malvinas es la historia y la ficción, su relato ha servido para sostener y derribar, gobiernos y 
soldados, civiles y militares, desde el siglo XIX al XXI. Por todo esto, desde la construcción misma del imaginario sobre las Islas, Malvinas es, sobre todo, el relato de una posibilidad. Y es en esa promesa potencial donde se inscribe también la literatura sobre la guerra. Llegados a 2018, a 36 años del enfrentamiento, puede asegurarse que Malvinas tiene su propio nicho ficcional y una crítica que acompaña las producciones. En el repaso de las principales obras puede verificarse que en los últimos años se está produciendo un relevo, de manera que la herencia de la memoria de la guerra es recuperada por una nueva generación. En los tres momentos propuestos se evidencian nuevos personajes, pero también otros que han permanecido como distinción: los desertores, los pícaros, los impostores, los excombatientes, los perpetradores, los fantasmas. Estos últimos cada vez más frecuentes. Lo fantasmagórico se impone como tendencia, como modo de construir sobre lo invisible, de pensar la inmaterialidad de los cuerpos (de los soldados que no regresaron y por extensión también el de los desaparecidos) y del territorio, desconocido pero propio. Se echan en falta más miradas femeninas sobre la guerra, no obstante, el camino ya ha comenzado a transitarse, como un gran tejido que se expande entre el ritual duelo y el acto de memoria.

\section{BIBLIOGRAFÍA}

Benjamin, Walter. "El narrador”. Para una crítica de la violencia y otros ensayos. Iluminaciones IV. Madrid: Taurus, 2001. 111-134.

Blanco, Oscar et al. "Trashumantes de neblina, no las hemos de encontrar". Revista Espacios 13 (1994): 82-86.

Borges, Jorge Luis. “Juan López y John Ward”. Los conjurados. Madrid: Alianza Editorial, 1985.

Bruña Bragado, María José y Guillermo Mira Delli-Zotti. "Ruinas del imaginario nacional argentino: contar Malvinas". Kamchatka. Revista de análisis cultural 1 (2013): 37-61.

Constitución de la Nación Argentina. [Consulta: 10/12/2016]. Disponible en: http://servicios. infoleg.gob.ar/infolegInternet/anexos/0-4999/804/norma.htm

Destéfanis Laura. "El diario del mayor X, informe clasificado del Descubrimiento y la (Re) Conquista de las Islas Malvinas (en Las Islas, Carlos Gamerro)". Anales de Literatura Hispanoamericana 44 (2015): 71-82.

Drucaroff, Elsa. Los prisioneros de la torre. Política, relatos y jóvenes en la postdictadura. Buenos Aires: Emecé, 2011.

"Malvinas: una mancha temática que aún sangra". Perfil 25 de marzo (2007): 8-10.

Esteban, Edgardo. "Palabras preliminares". Las otras islas. Buenos Aires: Alfaguara, 2012. 
Fogwill, Rodolfo. Los pichiciegos. Visiones de una batalla subterránea. 1982. Buenos Aires: Interzona Editora, 2006.

Galtieri, Leopoldo. "Discurso del 2 de abril de 1982". [Consulta: 08/01/2017]. Disponible en: https://www.youtube.com/watch? $\mathrm{v}=$ _xqwNsmzCbM

Gamerro, Carlos. Las Islas. 1998. Buenos Aires: Grupo Editorial Norma, 2007.

Guber, Rosana. ¿Por qué Malvinas? De la causa nacional a la guerra absurda. Buenos Aires: Fondo de Cultura Económica, 2001.

Kohan, Martín. Dos veces junio. 2002. Buenos Aires: Sudamericana, 2008.

Ciencias Morales. 2007. Buenos Aires: Anagrama, 2010.

El país de la guerra. Buenos Aires: Eterna Cadencia, 2014.

Luis Mora, Vicente. "Puentes literarios e históricos entre Argentina y España". El taco en la Brea 2 (2014): 222-253.

Ratto, Patricia. Trasfondo. Buenos Aires: Adriana Hidalgo, 2012.

Ramos Acevedo, Jairo. "El "uti possidetis" un principio americano y no europeo". Misión Jurídica. Revista de Derecho y Ciencias Sociales 5 (2012): 145-163.

Romero, Luis Alberto, coord. La Argentina en la escuela. La idea de nación en los textos escolares. Buenos Aires: Siglo XXI, 2004.

Soriano, Osvaldo. A sus plantas rendido un león. Madrid: Mondadori, 1987.

Svetliza, Exequiel. "Escribir Malvinas según pasan las generaciones". Jornaleros. Revista científica de estudios literarios y lingüísticos 2; 11-2015; 108-119

Torbado, Jesús y Manuel Leguineche. Los topos. Barcelona: Círculo de Lectores, 1978.

Tennenini, Roberta. "El contradiscurso de la memoria en Los pichiciegos de Rodolfo Fogwill". Amerika 16 (2017). [Consulta: 03/12/2017]. Disponible en: http://journals.openedition. org/amerika/7859

Vitullo, Julieta. Islas Imaginadas. La guerra de Malvinas en la literatura y el cine argentinos. Buenos Aires: Corregidor, 2012. 